\title{
OPTIMIZATION OF WHEAT BRAN MEDIUM PROCESSING CONDITIONS, ASSESSMENT OF BIOLOGICAL VALUE FOR SACCHAROMYCES
}

Victor Panfilov $^{1}$, Boris Karetkin ${ }^{2}$, Mariya Gordienko ${ }^{3}$, Irina Shakir ${ }^{4}$

\begin{abstract}
Biotechnological methods have perhaps the greatest potential in deep processing of renewable raw materials. Bioconversion of lignocelluloses materials substantially increases its bioavailability and effectiveness of consumption by microorganisms. The enzymatic and chemical hydrolysis of wheat bran under mild conditions are compared in this study.

The purpose of this study was to define microbiological and biochemical criteria for the bioconversion. Enzymatic hydrolysis of extruded bran was held with three enzyme preparations usually used in the conversion of vegetable raw materials: "Viscoferm," "Cellic HTec2," and "Celloviridin G20x." The central composite design was used for parameter optimization. Saccharomyces cerevisiae yeast was used for assessment of biological value of the slurry obtained. The content of crude protein of the product obtained was 1.9 times higher than the initial.
\end{abstract}

UDC Classification: 579.6: 663.1, DOI: http://dx.doi.org/10.12955/cbup.v3.638

Keywords: wheat bran, enzymes, central composite design, yeast

\section{Introduction}

Deep processing of renewable raw materials is a priority for the development of modern technology, and biotechnological methods have perhaps the greatest potential to address this problem. Wheat bran is a by-product of grain processing, known for its benefits to human health due to the balanced content of fiber. On the other hand, the biotechnological processing of materials also has a considerable potential due to the wide range of products that can be obtained through the microbial synthesis (Favaro, Basaglia, van Zyl, \& Casella, 2013; Palmarola-Adrados, Chotěborská, Galbe, \& Zacchi, 2005). Pretreatment of the substrate is a typical step in bioconversion of lignocelluloses materials, which substantially increases its bioavailability and effectiveness of consumption by microorganisms (Albores, Pianzzola, Soubes, \& Cerdeiras, 2006; Eyini, Rajapandy, Parani, \& Lee, 2004).

In this case, acid hydrolysis under severe conditions is typical. Although for the substrates, which along with the pulp, contain a large amount of polysaccharides, such as starch less resistant to chemical and thermal stresses, this approach is not justified. The wastes make it environmentally unfriendly.

The chemical hydrolysis under mild conditions may be an alternative. Significant progress in the use of enzyme preparations also allows us solve this problem with high economic and environmental efficiency (Favaro, Basaglia, \& Casella, 2012).

The purpose of this study was to compare the mild acid and enzymatic hydrolysis of wheat bran based on microbiological and biochemical criteria for the following bioconversion.

\section{Materials and methodology}

Raw material used in this research, dry extruded wheat bran (residual moisture less than 10\%), was purchased from local manufacturer. The characteristics of the plant raw material are shown in Table 1.

\footnotetext{
${ }^{1}$ Victor Panfilov, Biotechnology Department, Faculty of Biotechnology and Industrial Ecology, D. Mendeleyev University of Chemical Technology of Russia, vip@muctr.ru

${ }^{2}$ Dmitry Baurin, Biotechnology Department, Faculty of Biotechnology and Industrial Ecology, D. Mendeleyev University of Chemical Technology of Russia

3 Mariya Gordienko, Biotechnology Department, Faculty of Biotechnology and Industrial Ecology, D. Mendeleyev University of Chemical Technology of Russia

${ }^{4}$ Irina Shakir, Biotechnology Department, Faculty of Biotechnology and Industrial Ecology, D. Mendeleyev University of Chemical Technology of Russia
} 


\begin{tabular}{|l|c|l|c|}
\hline \multicolumn{4}{|l|}{ Table 1: Basic biochemical parameters of secondary plant raw materials } \\
\hline \multicolumn{1}{|c|}{ Parameter } & Value & \multicolumn{1}{|c|}{ Parameter } & Value \\
\hline Dry weight, \% & 94.6 & Crude fiber, \% per dry weigh & 8.6 \\
\hline Crude protein, \% per dry weigh & 14.8 & Crude ash, \% per dry weigh & 5.3 \\
\hline
\end{tabular}

Source: Authors

Prior to hydrolysis, material was ground to a particle size of less than $1 \mathrm{~mm}$ (the predominant fraction of less than $0.5 \mathrm{~mm}$ ), weighed, and placed in Erlenmeyer flasks of $250 \mathrm{ml}$. The sample of tap water was poured according to water-to-material calculated ratio and the resulting volume of the hydrolysate $-100 \mathrm{ml} . \mathrm{pH}$ of the medium was adjusted using sulfuric acid solution and sodium hydroxide. Hydrolysis was carried out under excess pressure in the autoclave VK-75.

Studies on acid hydrolysis was carried out as follows: the exclusion of nonsignificant factors during fractional factorial experiment, the experiment according to the second order design with a variation on the significant factors, and search for the optimal conditions on the basis of the obtained regression equations. Temperature, water-to-material ratio, time, and initial $\mathrm{pH}$ of hydrolysis were varied during the acid hydrolysis.

Enzymatic hydrolysis of extruded bran was held with three enzyme preparations usually used in the conversion of vegetable raw materials: "Viscoferm" ("Novozymes," Denmark), "Cellic HTec2" ("Novozymes," Denmark) and "Celloviridin G20x" ("Rusferment," Russian Federation) (Cannella, Hsieh, Felby, \& Jørgensen, 2012; Haven \& Jørgensen, 2013).

Terms of enzymatic hydrolysis were different: introduced concentration of the enzyme preparation, pre-heating of the suspension, the optimal values of temperature and acidic $\mathrm{pH}$ (recommended by the manufacturer). Bran was suspended in distilled water at a ratio 1:20 to adjust the $\mathrm{pH}$ to the desired value before the hydrolysis using sulfuric acid.

The concentration of reducing sugars in the hydrolysates was determined by the Fehling method and total carbohydrates by the phenol-sulfur method.

To assess the growth properties of hydrolysates, yeast culture Saccharomyces cerevisiae race I, from the collection of the department of biotechnology Mendeleev University of Chemical Technology of Russsia, was used. Pre-hydrolysate was adjusted to $\mathrm{pH}$ 5,0 $\pm 0,1$ by using sodium hydroxide solution and then inoculated with overnight culture of yeast. Biomass accumulation was determined at 48 hours of growth by directly counting the number of cells in the Gorjaev's chamber (Hemocytometer).

Two standard experimental design techniques (fractional factor design and central composition design) were used. Statistical data processing was carried out in the MS Excel program.

\section{Results and Discussion}

\section{Acid hydrolysis}

In the first step of the investigation, the fractional factor design was used. Four factors were varied onto two levels: temperature (from 112 to $127^{\circ} \mathrm{C}$ ) $-X_{1}$, initial $\mathrm{pH}$ (from 2 to 4 ) $-X_{2}$, water-to-material ratio (from 10 to 20 ) $-X_{3}$, and hydrolisis time (from 30 to 45 minutes) $-X_{4}$. The concentration of reducing sugars $\left(Y_{1}\right)$ and yeast biomass yield $\left(Y_{2}\right)$ were selected as response variables.

The effect of each factor on both response variables, as well as the effects of interactions between factors on the response variables were found. The regression equations after exception of negligible coefficients are as follows:

$$
Y_{1}=13.5+2.0 X_{1}-11.2 X_{2}-1.7 X_{3}+0.5 X_{4}+1.2 X_{1} X_{2}-1.3 X_{1} X_{4}
$$




$$
Y_{2}=76.5+52.8 X_{2}-10.2 X_{3}-10.8 X_{1} X_{2}
$$

It was found that all factors significantly affected the concentration of reducing sugars, but in case of yield of yeast biomass the temperature and hydrolisis time were nonsignificant factors. Therefore, in the next step of investigation, these factors were constnt: the temperature at $112^{\circ} \mathrm{C}$ and the hydrolisis time of 30 minutes.

An important feature of the results is an almost complete absence of growth on yeast hydrolysates obtained at $\mathrm{pH} 0.5$, which is a consequence of the formation antinutrients. It should be noted that these experiments also showed significant darkening of the suspension after the hydrolysis, which may also be indicative of the formation of the compounds inhibiting the growth of yeast. Therefore, $\mathrm{pH}$ range was taken from 1.5 to 4.5 . The water-to-material ratio was varied from 8.7 to 20 .

The central composite design was used to obtain the second oder regression. The regression equations after exception of negligible coefficients are as follows:

$$
\begin{gathered}
Y_{1}=6.8-11.6 X_{2}-4.8 X_{3}+6.7 X_{2}^{2}+1.1 X_{3}^{2}+3.9 X_{2} X_{3} \\
Y_{2}=5.1-1.3 X_{3}-1.1 X_{2}^{2}+1.0 X_{3}^{2}
\end{gathered}
$$

Figure 1 presents the corresponding response surfaces.

Figure 1: Response surfaces

The optimal conditions were selected based on surface response of yeast biomass yield: $\mathrm{pH}$ of 3 and water-to-material ratio of 18 .

\section{Enzymatic hydrolysis}

Three enzyme preparations: "Viscoferm," "Cellic HTec2," and "Celloviridin G20x" were used. Figure 2 presents kinetics of reducing sugars production during hydrolysis.

In 90 minutes duration of hydrolysis, reducing sugars concentration approaches stationary. RS output amounted to $54 \%$ of the theoretically possible (under optimal) conditions. Mass of the dry residue after hydrolysis was reduced by $53.5 \%$, which is probably due to the release as a result of the destruction of cellulose in other compounds that make up the fiber.

In the case of "Celloviridin G20x," maximum reducing sugars concentration was achieved with 3\% dosage of enzyme preparation.

As can be seen from Figure 2b, the optimal dosage of "Cellic HTec2" is $12.5 \%$, while the yield of reducing sugars is $70 \%$ of the theoretically possible condition. This enzyme preparation contains $21.6 \%$ RS that was taken into account when assessing the effectiveness of the process. "Cellic HTec2" 
processing over 90 minutes does not affect the efficiency of hydrolysis. The dry weight of the residue decreased by $67 \%$ after hydrolysis with optimal enzyme dosage.

Preheating of the extruded bran slurry to $81{ }^{\circ} \mathrm{C}$ led to soaking and improved hydrolysis RS yield by 15 to $27 \%$.

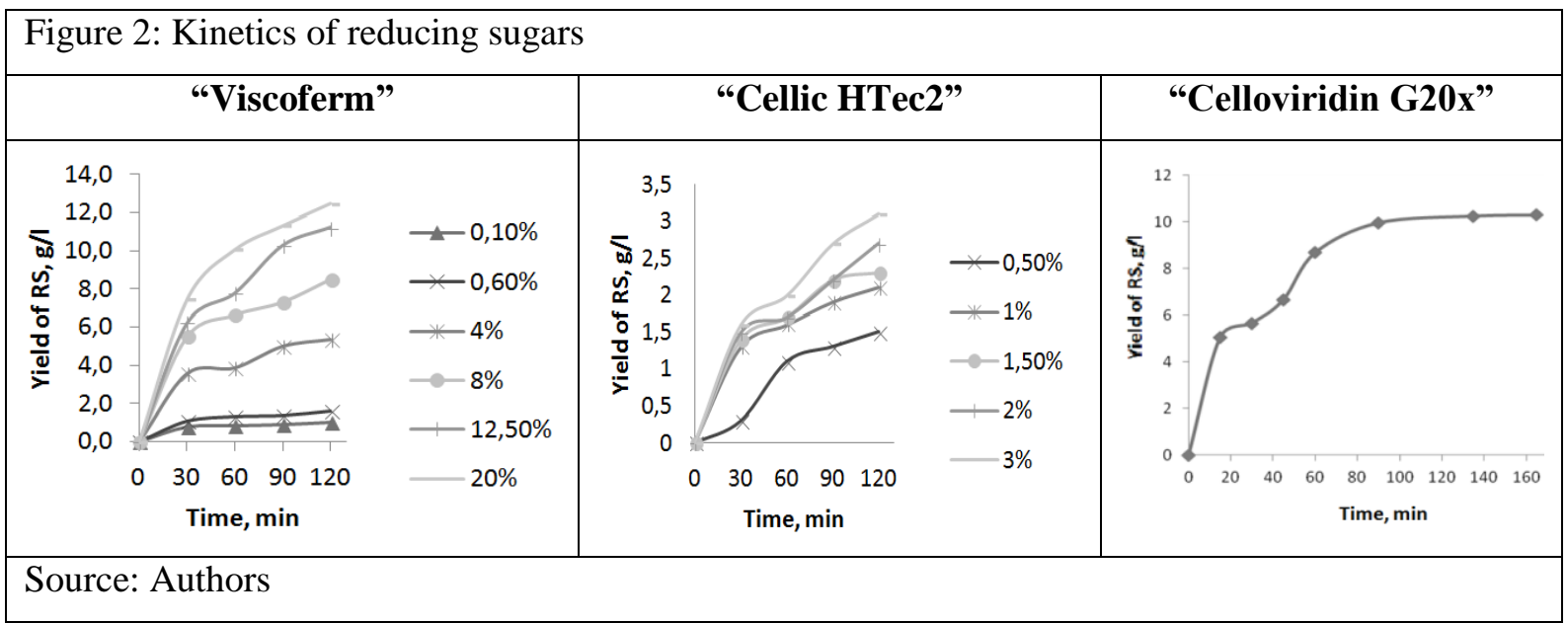

"Viscoferm" was applied with thermal pre-treatment and fractional introduction of the enzyme: first portion $(2.5 \%)$ - at the beginning of the process, the second (1.7\%) - after 45 minutes, and the third $(1.7 \%)$ - after 90 minutes of hydrolysis. Stationary concentration of reducing sugars was reached after about 90 minutes of hydrolysis, and the introduction of additional enzyme did not affect the specified amount. Reducing sugars and carbohydrates yield was $63.7 \%$ and $54.3 \%$, respectively. Weight of the solid phase after hydrolysis, was reduced by $58.5 \%$ (see Figure 2). Experiments showed that the thermal pre-treatment of the slurry can reduce the dosage of enzyme without hydrolysis efficiency loss. Duration of hydrolysis is 90 minutes, corresponding to the onset of the stationary phase in all the experiments. Fractional introduction of enzyme increases the yield of RS with a possible reduction of the concentration of enzymes. "Viscoferm" contains a complex of enzymes, some of which is present in "Celloviridin G20x" and "Cellic HTec2" compositions. Its use increases the RS by four times at the triple spending cuts of the enzyme. "Viscoferm" is suggested economically expedient to carry out the enzymatic hydrolysis.

Evaluation of the biological value of bran culture media obtained after acid and enzymatic hydrolysis For evaluation of the biological value of the culture media based of bran hydrolysates and to compare the effectiveness of enzymatic and acidic hydrolysis yeast fermentation was held on hydrolysates obtained in optimal conditions without separation of solids. The growth rate of culture, final consumption of the substrate (RS), product yield (yeast biomass), as well as biochemical characteristics were evaluated. Three variants of nutrient media for culturing yeast: after enzymatic hydrolysis of bran preparations "Viscoferm" (3,5\%) after acid hydrolysis (CG) bran $\left(127^{\circ} \mathrm{C}, \mathrm{pH} 3.21\right.$, 8.0 water-to-material ratio, and 30 minutes).

Process efficiency was evaluated by two parameters: reducing sugars yield and total carbohydrates.

Both are substrate for the yeast cultivation on hydrolysates as shown above.

The initial cell concentration was 4 million cells $/ \mathrm{ml}$. The growth curves of Saccharomyces cerevisiae and consumption substrate are shown in Figure 3.

The method of wheat bran hydrolysis as seen from the results had no significant effect on the specific growth rate, while the duration of the lag phase for enzymatic hydrolysates was significantly lower ( 1 hour) compared to acidic ( 3 hours). The stationary growth phase was reached at the $25^{\text {th }}$ hour of 
culture, while the maximum biomass yield in case of acid hydrolysis was lower than that for enzymatic.

\begin{tabular}{|l|l|l|}
\hline \multicolumn{2}{|c|}{ Figure 3: Growth kinetics of Saccharomyces cerevisiae on hydrolysates of wheat bran: } \\
\hline Enzymatic hydrolysate & Acid hydrolysate \\
\hline & & \\
\hline
\end{tabular}

The consumption rate decrease was observed for acid hydrolysate. The phenomenon observed can be explained by the chemical composition of the carbohydrates in the nutrient medium after the hydrolysis. Obviously, glucose will prevail after processing with cellulases and amylases, as it is readily assimilated substrate if compared with the monosaccharides produced of hemicellulose in acidic conditions. On the other hand, acid hydrolysis appears to be less expensive due to the costs of raw material, but it requires further production costs calculation.

\begin{tabular}{|l|r|r|r|r|r|}
\hline \multicolumn{1}{|c|}{ Table 2: Characteristics of Saccharomyces cerevisiae culture on hydrolyzed vegetable raw materials } \\
\hline \multicolumn{1}{|c|}{ Pronditions } & $\begin{array}{c}\text { Lag } \\
\text { growth } \\
\text { phase } \\
(\mathbf{h})\end{array}$ & $\begin{array}{c}\text { Specific } \\
\text { growth } \\
\text { rate } \\
\left(\mu_{\boldsymbol{x}}\right)\end{array}$ & $\begin{array}{c}\text { Specific substrate } \\
\text { consumption rate } \\
\left(\mu_{\boldsymbol{S}}\right)\end{array}$ & $\begin{array}{c}\text { Yield } \\
\left(\boldsymbol{Y}_{\boldsymbol{S}}^{\boldsymbol{x}}\right)\end{array}$ & $\begin{array}{c}\text { Substrate } \\
\text { consumption degree } \\
\left(\boldsymbol{\%} \boldsymbol{\eta}_{\boldsymbol{S}}\right)\end{array}$ \\
\hline $\begin{array}{l}\text { Wheat bran, acidic } \\
\text { processing }\end{array}$ & 1,0 & 0,161 & 0,041 & 0,56 & 86,9 \\
\hline $\begin{array}{l}\text { Wheat bran, } \\
\text { enzymatic } \\
\text { hydrolisys }\end{array}$ & 3,0 & 0,120 & 0,029 & 0,44 & $25,0 / 78,1$ \\
\hline Source: Authors & & & & \\
\hline
\end{tabular}

\section{Biochemical characteristics of the product}

Main biochemical parameters of the feedstock composition were compared with those of the resulting fodder biomass. Enzymatic hydrolysis of wheat bran can improve crude protein content 1.9 times and 1.6 times for acidic. Thus, enzymatic hydrolysate of wheat bran from the viewpoint of the growth kinetics and economic factor is more desirable.

Enzyme hydrolyzed bran is the most promising substrates. The product biomass has a high crude protein content, and substrate consumption is also significantly higher when cultured in the enzymatic bran hydrolysate, which makes the present method more eco-friendly. 


\section{Conclusion}

In the present study, the patterns of chemical and enzymatic hydrolysis of wheat bran were examined. Application of the experimental design methods allowed us to identify non-significant factors and determine the optimal conditions: hydronic $8.0, \mathrm{pH} 3.21$, the temperature of $127^{\circ} \mathrm{C}$, duration of 30 minutes, based on the analysis of the second order regression equations.

The study of enzymatic hydrolysis determined that the enzyme preparation "Viscoferm" allows us to obtain the greatest yield of reducing sugars in comparison with "Celloviridin G20x" and "Cellic HTec2" preparations. The following conditions were recommended: $3.5 \%$ enzyme concentration and 90 minutes.

The content of crude protein in the product obtained on enzymatic hydrolisate was $28.0 \%$ that is 1.9 times higher than initial.

The research is supported by the Ministry of Education and Science of the Russian Federation within the framework of basic component of the State Assignment.

\section{References}

Albores, S., Pianzzola, M. J., Soubes, M., \& Cerdeiras, M. P. (2006). Biodegradation of agroindustrial wastes by Pleurotus spp for its use as ruminant feed. Electronic Journal of Biotechnology, 9(3). doi:10.2225/vol9-issue3-fulltext-2

Cannella, D., Hsieh, C. C., Felby, C., \& Jørgensen, H. (2012). Production and effect of aldonic acids during enzymatic hydrolysis of lignocellulose at high dry matter content. Biotechnology for Biofuels.

Eyini, M., Rajapandy, V., Parani, K., \& Lee, M.-W. (2004). Effect of Different Pretreatment Methods on the Bioconversion of Rice Bran into Ethanol. Mycobiology, 32(4), 170-172.

Favaro, L., Basaglia, M., \& Casella, S. (2012). Processing wheat bran into ethanol using mild treatments and highly fermentative yeasts. Biomass and Bioenergy, 46, 605-617.

Favaro, L., Basaglia, M., van Zyl, W. H., \& Casella, S. (2013). Using an efficient fermenting yeast enhances ethanol production from unfiltered wheat bran hydrolysates. Applied Energy, 102, 170-178.

Haven, M. O., \& Jørgensen, H. (2013). Adsorption of $\beta$-glucosidases in two commercial preparations onto pretreated biomass and lignin. Biotechnology for Biofuels, 6(1), 165. Retrieved from http://www.ncbi.nlm.nih.gov/pubmed/24274678

Palmarola-Adrados, B., Chotěborská, P., Galbe, M., \& Zacchi, G. (2005). Ethanol production from non-starch carbohydrates of wheat bran. Bioresource Technology, 96(7), 843-850. 